\title{
A pyridinium/anilinium [2]catenane that operates as an acid-base driven optical switch
}

\author{
Sarah J. Vella and Stephen J. Loeb*
}

\author{
Full Research Paper \\ Address: \\ Department of Chemistry and Biochemistry, University of Windsor, \\ Windsor, Ontario N9B 3P4, Canada

\section{Email:} \\ Stephen J. Loeb ${ }^{*}$ - loeb@uwindsor.ca \\ * Corresponding author \\ Keywords: \\ catenane; mechanically interlocked molecule; molecular switch
}

Beilstein J. Org. Chem. 2018, 14, 1908-1916.

doi:10.3762/bjoc. 14.165

Received: 28 April 2018

Accepted: 05 July 2018

Published: 25 July 2018

This article is part of the thematic issue "Macrocyclic and supramolecular chemistry".

Guest Editor: M.-X. Wang

(C) 2018 Vella and Loeb; licensee Beilstein-Institut.

License and terms: see end of document.

\begin{abstract}
A two-station [2] catenane containing a large macrocycle with two different recognition sites, one bis(pyridinium)ethane and one benzylanilinium, as well as a smaller DB24C8 ring was synthesized and characterized. ${ }^{1} \mathrm{H}$ NMR spectroscopy showed that the DB24C8 ring can shuttle between the two recognition sites depending on the protonation state of the larger macrocycle. When the aniline group is neutral, the DB24C8 ring resides solely at the bis(pyridinium)ethane site, while addition of acid forms a charged benzylanilinium site. The DB24C8 then shuttles between the two charged recognition sites with occupancy favoring the bis(pyridinium)ethane site by a ratio of 4:1. The unprotonated [2]catenane has a deep yellow/orange color when the DB24C8 ring resides solely at the bis(pyridinium)ethane site and changes to colorless when the crown ether is shuttling (i.e., circumrotating) back and forth between the two recognition sites thus optically signalling the onset of the shuttling dynamics.
\end{abstract}

\section{Introduction}

[2]Rotaxane molecular shuttles [1-5] are the dynamic building blocks of a wide variety of molecular switches [6-9] and a number of sophisticated molecular machines that operate away from equilibrium [10-15]. We have previously reported [2]rotaxane molecular switches containing a single dibenzo[24]crown ether DB24C8 wheel and two different recognition sites; benzylanilinium and 1,2-bis(pyridinium)ethane [16]. These shuttles operate as bistable switches driven by acid/ base chemistry and can be optically sensed by either a change in color (yellow/colorless) for $[\mathbf{1 F} \subset \mathbf{D B 2 4 C 8}]^{2+}$ or a fluorescence change $(\mathrm{OFF} / \mathrm{ON})$ for $[\mathbf{1 A \subset D B 2 4 C 8}]^{2+}$; see Figure 1.

In addition, we have also previously prepared a [3]catenane containing two dibenzo[24]crown ether DB24C8 rings interlocked onto a much larger macrocyclic ring containing two 1,2bis(pyridinium)ethane recognition sites linked by terphenyl spacer groups [17] (Figure 2). 
a)
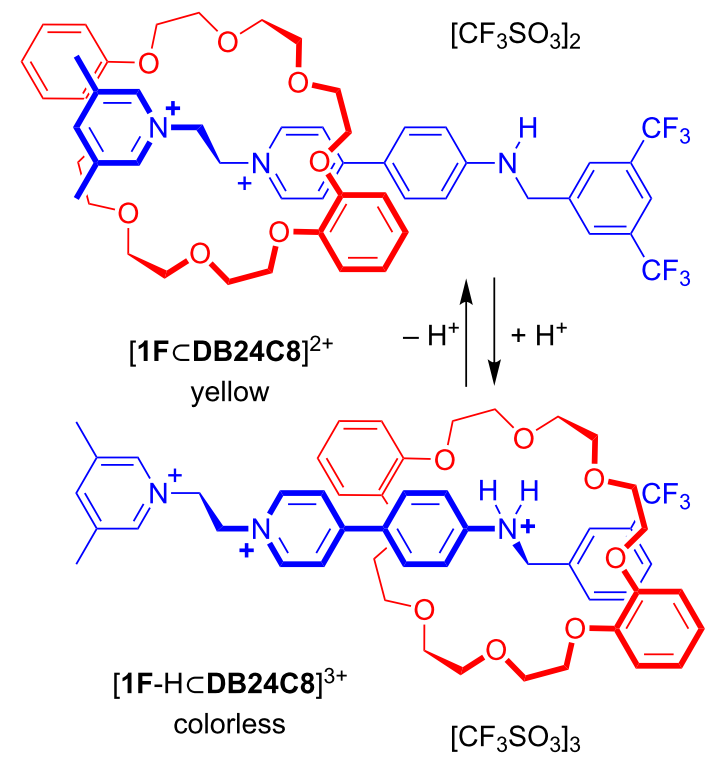

b)
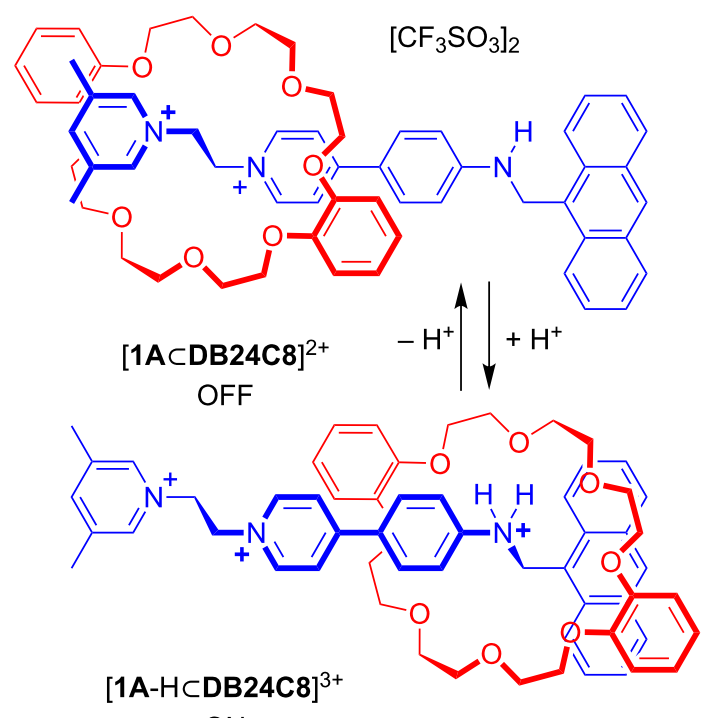

ON

$\left[\mathrm{CF}_{3} \mathrm{SO}_{3}\right]_{3}$

Figure 1: Two [2]rotaxane molecular shuttles with both bis(pyridinium)ethane and benzylanilinium recognition sites that can be switched by acid-base chemistry and optically sensed by a) a color change from colorless to yellow and b) a change in fluorescence from $O F F$ to $O N\left(C D_{3} C N\right.$ or $\left.C D_{2} C l_{2}\right)$.

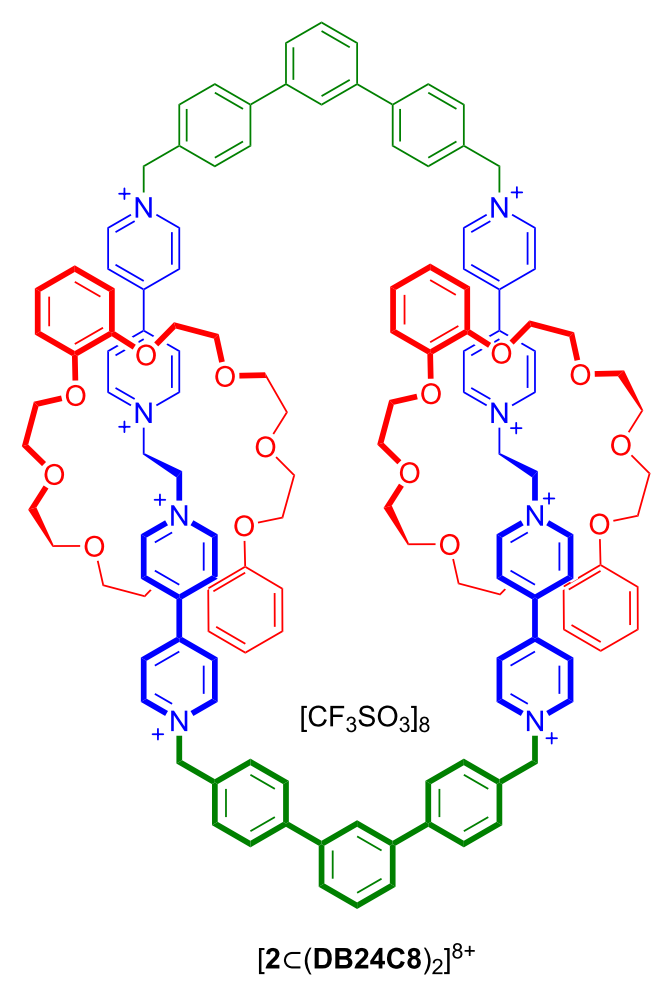

Figure 2: A [3]catenane containing two identical bis(pyridinium)ethane recognition sites on a large macrocycle and two smaller threaded DB24C8 rings.
It was thus of interest to design and build these two different recognition sites (benzylanilinium and bis(pyridinium)ethane) into an analogous circumrotational [2]catenane molecular switch to compare to the linear [2]rotaxane molecular shuttles outlined in Figure 1. This should be possible because of the structural similarities (size and shape) between the bis(pyridinium)ethane and benzylanilinium recognition sites. Each has a two-atom chain in a low energy, anti-conformation linking aromatic rings and the distance between the terminal nitrogen atoms are 18.11 and $18.09 \AA$ (MM3) for the benzylaniline and bis(dipyridinium)ethane axles $\mathbf{4}$ and $\mathbf{5}^{2+}$, respectively; see Figure 2 and Scheme 1 compound $[\mathbf{8} \subset \mathbf{D B 2 4 C 8}]^{6+}$ for this comparison and concept.

\section{Results and Discussion \\ Synthesis}

Although the previously reported [3]catenane (Figure 2) was synthesized using a one-step, self-assembly procedure from two bis(pyridinium)ethane axles, two terphenyl spacers and two DB24C8 crown ethers, a [2]catenane with different recognition sites requires a stepwise approach involving the incorporation of each recognition site independently. Overall, the synthesis of $[2]$ catenane $[\mathbf{8} \subset \mathbf{D B 2 4 C 8}]^{6+}$ required multiple steps and is outlined in Scheme 1. Two literature preparations were used to construct each of the known compounds, terphenyl linker 6 [18] and bis(pyridinium)ethane axle [5][OTf $]_{2}[19,20]$, while the new benzylaniline axle 4 was prepared as shown from 3 [21]. 

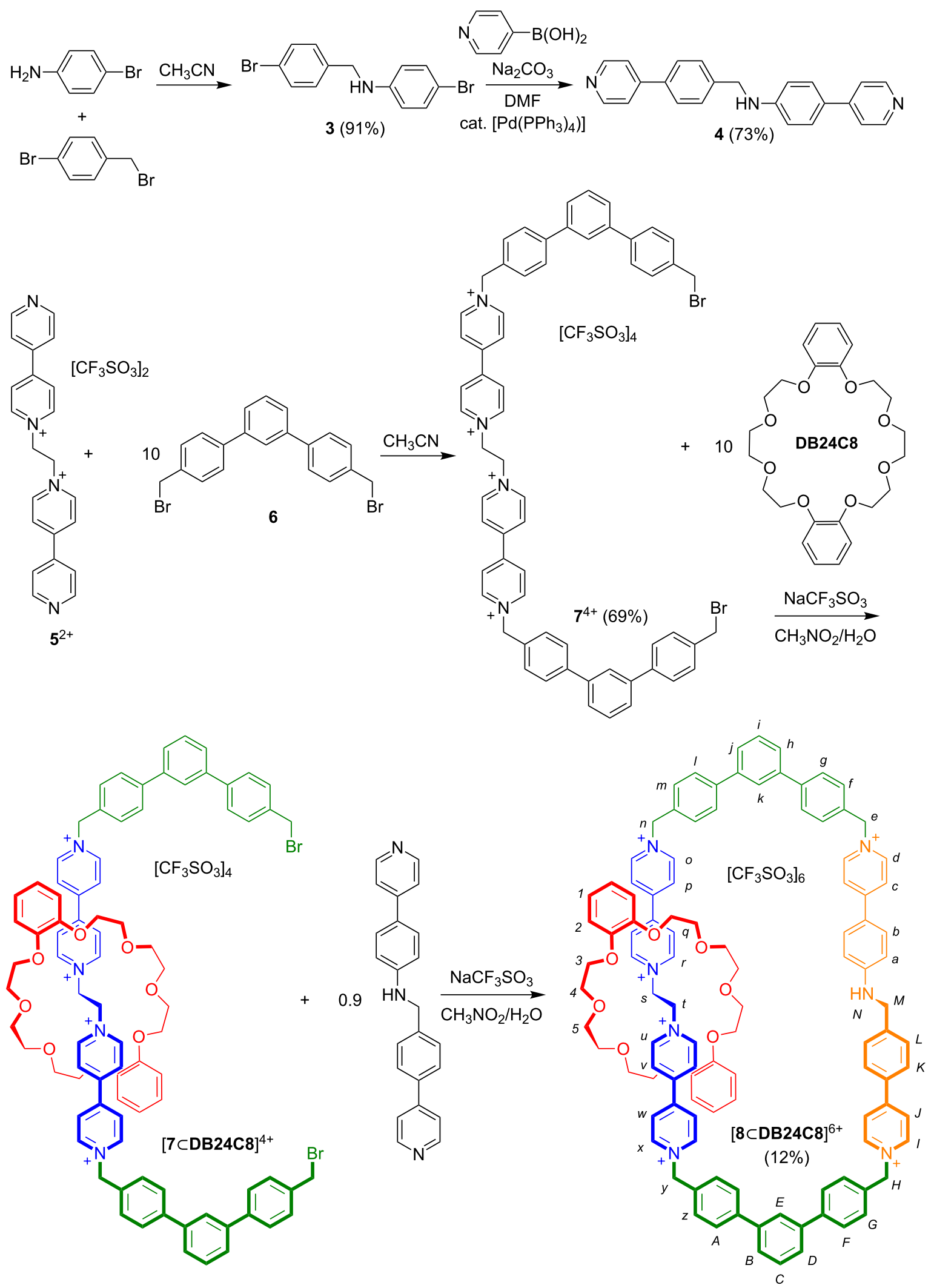

Scheme 1: Step-wise synthesis of [2]catenane $[\mathbf{8} \subset \mathrm{DB} 24 \mathrm{C} 8]^{6+}$ containing benzylanilinium and bis(pyridinium)ethane recognition sites and terphenyl spacers. 
Once the precursor components were synthesized, the [2]catenane was assembled in two steps. Firstly, [5][OTf $]_{2}$ was reacted with ten equivalents of the bis(bromomethyl)terphenyl linker 6 in $\mathrm{CH}_{3} \mathrm{CN}$ to afford [7][OTf] $]_{4}$ in moderate yield. Secondly, the [2]pseudorotaxane [7CDB24C8 $]^{4+}$ was formed using [7][OTf $]_{4}$ in the presence of DB24C8 followed by ring closure using the benzylaniline axle 4 to yield $[\mathbf{8} \subset \mathbf{D B 2 4 C 8}][\mathrm{OTf}]_{6}$. The reaction was performed under dilute conditions with 10 equivalents of crown ether to favor ring closure and kinetic trapping of the smaller ring.

To isolate the pure [2]catenane, the reaction solvent $\left(\mathrm{CH}_{3} \mathrm{CN}\right)$ was evaporated and the residue washed with toluene to remove excess crown ether. This was then followed by column chromatography on silica gel using a 5:3:2 mixture of $\mathrm{CH}_{3} \mathrm{OH} /$ $2 \mathrm{M} \mathrm{NH}_{4} \mathrm{Cl} / \mathrm{CH}_{3} \mathrm{NO}_{2}$ as the eluent. Fractions containing the product $\left(R_{\mathrm{f}}=0.66\right)$ were combined and anion exchanged to the triflate salt to yield [2]catenane $[\mathbf{8} \subset \mathbf{D B 2 4 C 8}][\mathrm{OTf}]_{6}$.

\section{Characterization}

The ${ }^{1} \mathrm{H}$ NMR spectrum of [2] catenane $[\mathbf{8} \subset \mathbf{D B} 24 \mathbf{C 8}]^{6+}(298 \mathrm{~K}$, $\mathrm{CD}_{2} \mathrm{Cl}_{2}$ ) is shown in Figure 3 and the labelling scheme for the $\mathrm{H}$-atoms is given in Scheme 1. All resonances were assigned based on 2D COSY NMR spectroscopy as well as comparison to ${ }^{1} \mathrm{H}$ NMR and COSY spectra of individual components 6 and $7^{4+}$. Comparing the proton chemicals shifts for H-atoms $n-y$ of $[\mathbf{8} \subset \mathrm{DB} 24 \mathrm{C} 8]^{6+}$ with those of precursor $7^{4+}$ shows changes in chemical shift typically associated with the close interaction of DB24C8 with a bis(pyridinium)ethane recognition site [18]. In particular, the significant downfield shifts observed for ethylene protons $s$ and $t$ from $5.30 \mathrm{ppm}$ in $7^{4+}$ to $5.56 \mathrm{ppm}$ for $[8 \subset \mathrm{DB} 24 \mathrm{C8}]^{6+}$ as well as $u$ and $r$, the ortho pyridinium protons, from $9.04 \mathrm{ppm}$ in $7^{4+}$ to $9.31 \mathrm{ppm}$ for $[\mathbf{8} \subset \mathbf{D B 2 4 C 8}]^{6+}$ are characteristic of hydrogen-bonding to the crown ether. In addition, $\pi$-stacking interactions induce upfield shifts for protons $p, q, v$ and $w$ from $8.48 \mathrm{ppm}$ in $7^{4+}$ to $8.24 \mathrm{ppm}$ for $[8 \subset \text { DB24C8 }]^{6+}$. Protons $o, x, n$ and $y$ do not shift appreciably because the crown ether does not extend far enough to interact with these protons. In contrast, the chemical shifts for protons $a-d$ and $I-L$ on the benzylaniline portion of the large ring of $[8 \subset \text { DB24C8 }]^{6+}$ do not shift significantly inferring that in the neutral aniline state the crown ether resides exclusively at the bis(pyridinium)ethane site of the [2]catenane. Table 1 summarizes the chemical shift differences between the [2]catenane $[8 \subset \mathrm{DB24C8}]^{6+}$ and precursor $7^{4+}$ which contains no crown ether.

A sample of $[\mathbf{8} \subset \mathbf{D B 2 4 C 8}]^{6+}\left(1: 1 \mathrm{CH}_{3} \mathrm{OH} / \mathrm{CH}_{3} \mathrm{CN}\right)$ was analyzed by high-resolution electrospray mass spectrometry (HRESIMS). Sufficient resolution for each of the $2+, 3+, 4+$ and $5+$ molecular ions allowed for exact mass measurements $(<5 \mathrm{ppm})$ confirming the catenated nature of the structure. Table 2 summarizes the observed values.

\section{Acid-base driven switching}

The analysis of the ${ }^{1} \mathrm{H}$ NMR spectrum $\left(\mathrm{CD}_{3} \mathrm{CN}, 298 \mathrm{~K}\right)$ of $[8 \subset \mathrm{DB24C8}]^{6+}$ indicates that the DB24C8 ring resides exclusively at the bis(pyridinium)ethane recognition site. This is

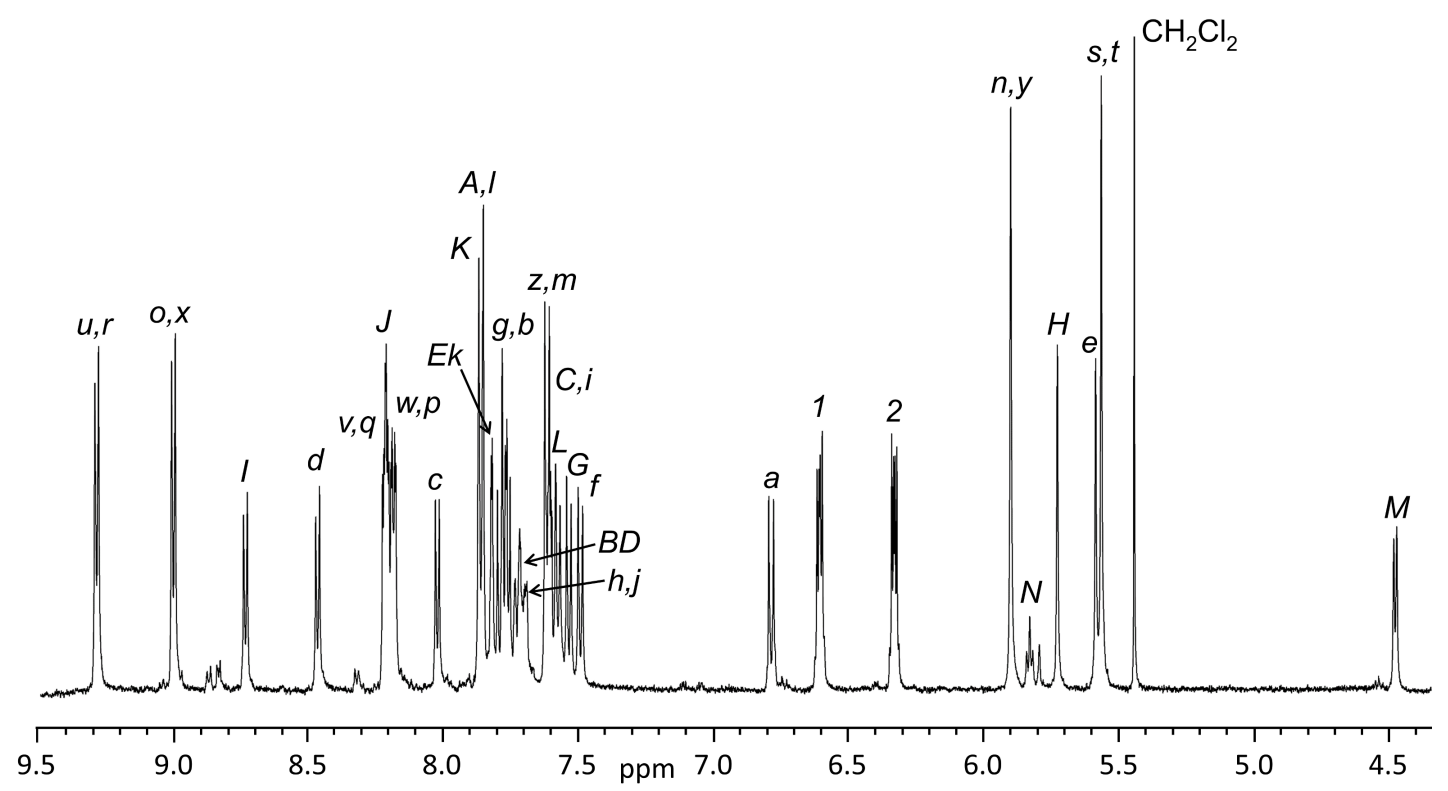

Figure 3: ${ }^{1} \mathrm{H}$ NMR spectrum of [2]catenane $[8 \subset \mathrm{CDB} 24 \mathrm{C} 8]^{6+}\left(500 \mathrm{MHz}, 298 \mathrm{~K}, \mathrm{CD}_{2} \mathrm{Cl}_{2}\right)$ showing the assigned proton chemical shifts; see Scheme 1 for labelling. 
Table 1: Summary of major chemical shift differences between precursor $7^{4+}$ and catenane $[8 \subset D B 24 C 8]^{6+}$.

\begin{tabular}{ccc} 
protons $^{a}$ & $\mathbf{7}^{4+}$ & {$[\mathbf{8} \subset \mathbf{D B 2 4 C 8}]^{6+}$} \\
\hline$n, y$ & 5.89 & 5.90 \\
$o, x$ & 9.05 & 9.03 \\
$p, w$ & 8.47 & 8.19 \\
$q, v$ & 8.50 & 8.22 \\
$r, u$ & 9.04 & 9.31 \\
$s, t$ & 5.30 & 5.56 \\
\hline
\end{tabular}

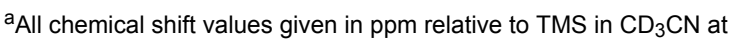
$298 \mathrm{~K}$

easily understood as the neutral benzylaniline site does not allow for appreciable non-covalent interactions and cannot compete for the DB24C8 ring with the dicationic bis(pyridinium)ethane site. However, the addition of one equivalent of triflic acid $\left(\mathrm{CF}_{3} \mathrm{SO}_{3} \mathrm{H}\right)$ to a solution of $[\mathbf{8} \subset \mathbf{D B 2 4 C 8}]^{6+}$ results in protonation of the aniline nitrogen atom to give $[8-\mathrm{H} \subset \mathrm{DB} 24 \mathrm{C} 8]^{7+}$ and a second viable recognition site for the crown ether.

Figure 4 shows a partial ${ }^{1} \mathrm{H}$ NMR spectrum of protonated $[8-\mathrm{H} \subset \mathbf{D B 2 4 C 8}]^{7+}$ in $\mathrm{CD}_{3} \mathrm{CN}$ at $298 \mathrm{~K}$. The smaller DB24C8 ring can now reside at either of the bis(pyridinium)ethane or benzylanilinium sites and these two possible co-conformations are designated $\mathbf{A}$ and $\mathbf{B}$ in Figure 4a. The ethylene protons at the core of the bis(pyridinium)ethane motif, labelled $s$ and $t$ in $\mathbf{A}$ and $s$ ' and $t^{\prime}$ in $\mathbf{B}$ are clearly distinguishable and show that there is a 4:1 ratio of $\mathbf{A}: \mathbf{B}$ indicating that the smaller DB24C8 ring prefers to occupy the bis(pyridinium)ethane site over the benzylanilinium site and that shuttling between the two sites is slow on the NMR timescale under these experimental conditions. Addition of base $\left(\mathrm{NEt}_{3}\right)$ returns the system to its original state and the process can be cycled by repeated addition of acid $\left(\mathrm{CF}_{3} \mathrm{SO}_{3} \mathrm{H}\right)$ and base without significant degradation of the compound as verified by ${ }^{1} \mathrm{H}$ NMR spectroscopy.

Interestingly, these results are contrary to those observed for the [2]rotaxane molecular shuttles $[\mathbf{1 F} \subset \mathbf{D B 2 4 C 8}]^{2+}$ and $[\mathbf{1 A \subset D B 2 4 C 8}]^{2+}$ shown in Figure 1. For that system, the benzylanilinium site was preferred 3:1 for $[\mathbf{1 F} \subset \mathbf{D B 2 4 C 8}]^{2+}$ and 9:1 for $[\mathbf{1 A} \subset \mathbf{D B 2 4 C 8}]^{2+}$ in $\mathrm{CD}_{3} \mathrm{CN}$ and when $\mathrm{CD}_{2} \mathrm{Cl}_{2}$ was used the systems were completely bistable with DB24C8 preferring to reside exclusively at the bis(pyridinium)ethane site when unprotonated and exclusively at the benzylanilinium site when protonated.

The UV-visible spectra of $[\mathbf{8} \subset \mathbf{D B 2 4 C 8}]^{6+}$ and $[8-H \subset D B 24 C 8]^{7+}$ are shown in Figure 5 for $2.0 \times 10^{-5} \mathrm{M}$ solutions in $\mathrm{CH}_{3} \mathrm{CN}$. The molar absorptivity $(\varepsilon)$ of $[\mathbf{8} \subset \mathbf{D B 2 4 C 8}]^{6+}$ was calculated to be $22,680 \mathrm{~L} \mathrm{~mol}^{-1} \mathrm{~cm}^{-1}$ with $\lambda_{\max }$ at $412 \mathrm{~nm}$. The large absorption is due to an intramolecular charge transfer (ICT) band arising from charge transfer between the aniline nitrogen and pyridinium group of the benzylanilinium recognition site. However, this ICT band (412 nm) is eliminated by protonating the aniline nitrogen to form $[8-\mathrm{H} \subset \mathbf{D B 2 4 C 8}]^{7+}$. Therefore, when the [2]catenane absorbs strongly showing a deep yellow/orange solution this indicates that the crown resides solely on the bis(pyridinium)ethane site for $[8 \subset \text { DB24C8 }]^{6+}$ but, when the [2]catenane does not absorb in the UV-visible region yielding a colorless solution this means the crown ether must be shuttling (i.e., circumrotating) back and forth between the two co-conformations, $\mathbf{A}$ and $\mathbf{B}$, of $[8-\mathrm{H} \subset \mathrm{DB} 24 \mathrm{C8}]^{7+}$.

\section{Conclusion}

A two-station circumrotational [2]catenane has been synthesized and its operation described. The system consists of a large macrocycle containing two different recognition sites, one bis(pyridinium)ethane and one benzylanilinium with a single smaller DB24C8 ring that can shuttle between the two recognition sites depending on the protonation state of the larger macrocycle. When the aniline group is neutral, the DB24C8 ring resides only at the bis(pyridinium)ethane site. However, addition of acid activates the benzylanilinium site allowing the ring to shuttle between the two, now competing, recognition sites. It was found that DB24C8 prefers the bis(pyridinium)ethane site over the protonated benzylanilinium site in a ratio of 4:1. This is quite different from similar [2] rotaxane molecular shuttles (Figure 1) where, once protonated, the benzylanilinium

Table 2: Summary of major HRESIMS peaks for catenane [8СDB24C8] ${ }^{6+}$

\begin{tabular}{cccc} 
molecular ion & calculated $\mathrm{m} / \mathrm{z}$ & experimental $m / \mathrm{z}$ & $\Delta(\mathrm{ppm})$ \\
\hline$\left.\{\mathbf{8} \subset \mathrm{DB24C8}][\mathrm{OTf}]_{4}\right\}^{2+}$ & 1116.7969 & 1116.7972 & 0.3 \\
$\left\{[\mathbf{8} \subset \mathrm{DB24C8}][\mathrm{OTf}]_{3}\right\}^{3+}$ & 694.8804 & 694.8835 & 4.5 \\
$\left\{[\mathbf{8} \subset \mathbf{D B 2 4 C 8}][\mathrm{OTf}]_{2}\right\}^{4+}$ & 483.9222 & 483.9246 & 5.0 \\
$\{[\mathbf{8} \subset \mathbf{D B 2 4 C 8}][\mathrm{OTf}]\}^{5+}$ & 357.3472 & 357.3465 & 2.0
\end{tabular}



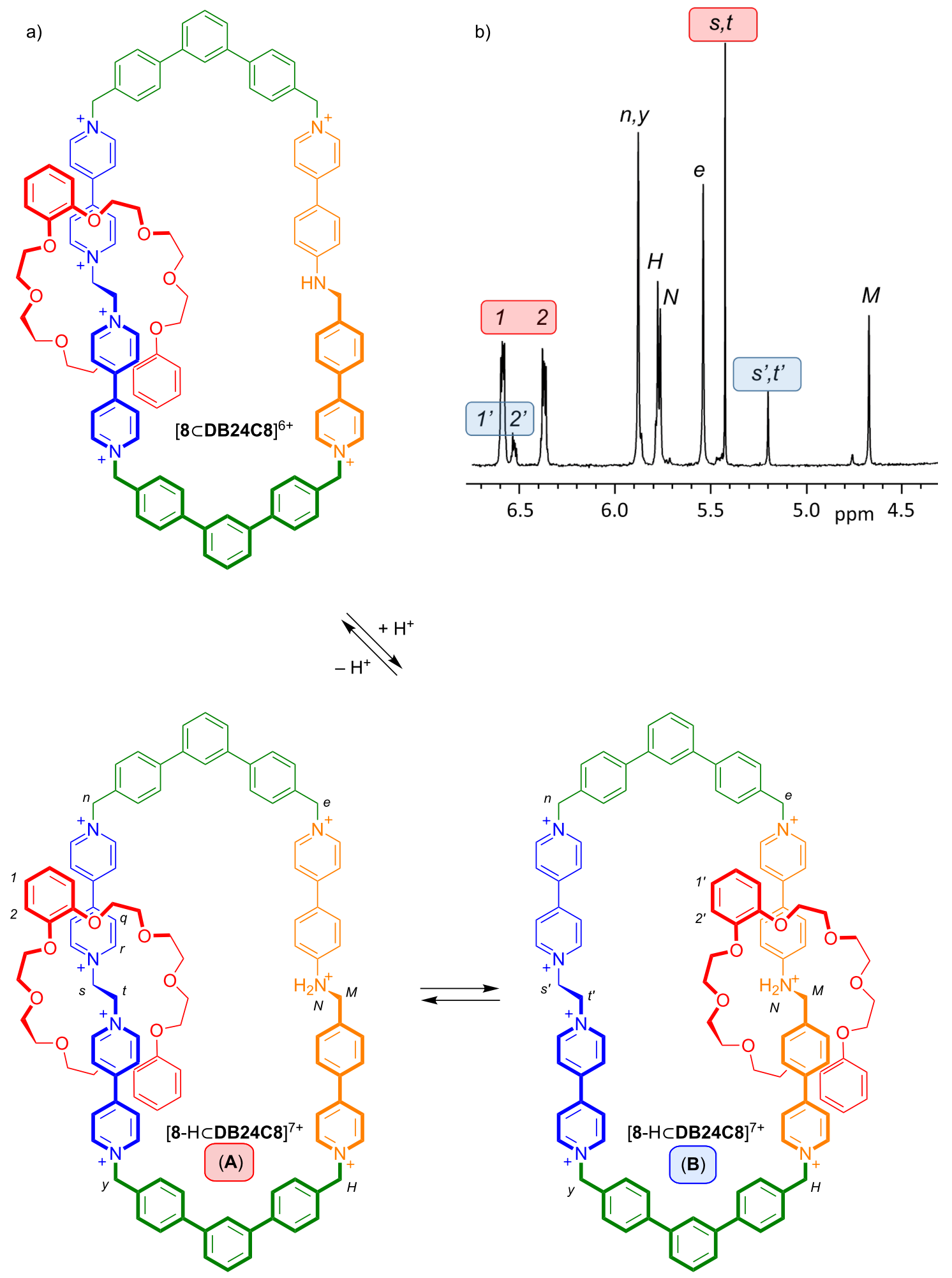

Figure 4: a) The [2]catenane [8CDB24C8 ${ }^{6+}$ can be protonated to yield [8-HCDB24C8] ${ }^{7+}$ in two different co-conformations $\mathbf{A}$ and $\mathbf{B}$. b) The partial ${ }^{1} \mathrm{H}$ NMR spectrum $\left(500 \mathrm{MHz}, 298 \mathrm{~K}, \mathrm{CD}_{3} \mathrm{CN}\right)$ of $[8-\mathrm{HCDB24C8}]^{7+}$ shows key resonances for both co-conformations $\mathbf{A}$ (red) and $\mathbf{B}$ (blue). See Scheme 1 for labelling; atoms of co-conformer $\mathbf{B}$ are labelled with a prime, e.g., $s$ ' versus $s$. 


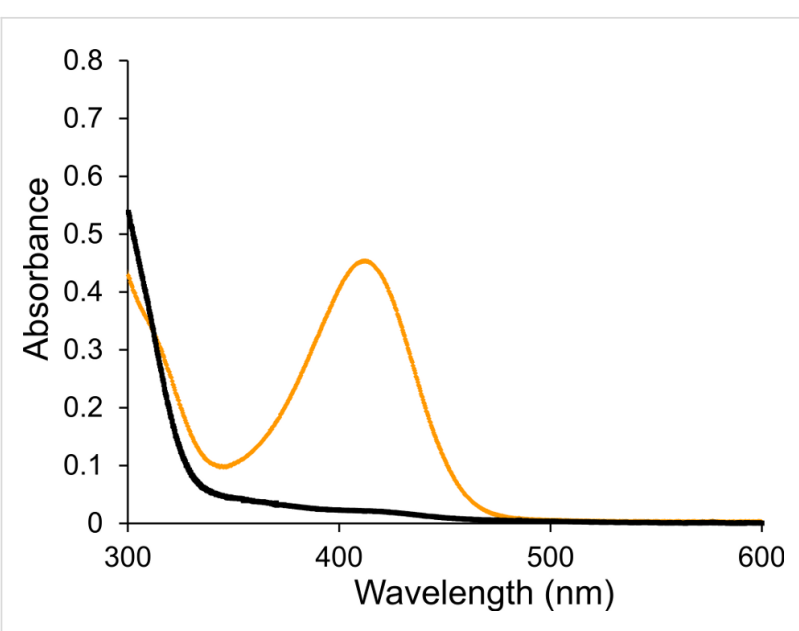

Figure 5: UV-visible spectra of [8СDB24C8] ${ }^{6+}$ (orange trace) and $[8-\mathrm{HCDB24C8}]^{7+}$ (black trace) in $\mathrm{CH}_{3} \mathrm{CN}$ solution at $2.0 \times 10^{-5} \mathrm{M}$ and $298 \mathrm{~K}$.

site was preferred $\left(\mathrm{CD}_{3} \mathrm{CN}\right)$ and in some cases exclusively $\left(\mathrm{CD}_{2} \mathrm{Cl}_{2}\right)$ generating a true ON/OFF bistable switch; unfortunately, the [2]catenane switch is insoluble in $\mathrm{CD}_{2} \mathrm{Cl}_{2}$ when protonated so a comparison could not be undertaken in this solvent. This difference in site populations between [2]rotaxane and [2]catenane is due to the presence of electron-withdrawing $\mathrm{CF}_{3}$ groups on the [2] rotaxane which make the benzylanilinium site more favorable in this case. Since it is fairly straightforward to change the nature of the stoppering groups of a [2]rotaxane dumbbell while the cyclic nature of the large ring makes it difficult to derivatize, [2] rotaxanes are deemed easier to fine-tune from a structural perspective than [2]catenanes. Although we were able to create an optically sensitive [2]catenane molecular shuttle with the bis(pyridinium)ethane and benzylanilinium recognition motifs, we could not achieve the true ON/OFF, bistable molecular switching previously observed for analogous [2]rotaxanes.

\section{Experimental}

\section{General comments}

4-Bromobenzyl bromide, 4-bromoaniline, 4-pyridylboronic acid, 1,3-dichlorobenzene, $p$-tolylmagnesium bromide, $n$-butyllithium and $N$-bromosuccinimide were purchased from Aldrich and used as received. Benzoyl peroxide was purchased from Acros and used as received. Compounds 3 [18], [5][OTf] $[19,20]$ and 6 [21] were prepared using literature methods. Solvents were dried using an Innovative Technologies solvent purification system. Thin-layer chromatography (TLC) was performed using Teledyne Silica gel 60 F254 plates and viewed under UV light. Column chromatography was performed using Silicycle ultra-pure silica gel (230-400 mesh). The solvents were dried and distilled prior to use. NMR spectra were recorded on a Bruker Avance III console equipped with an
11.7 $\mathrm{T}$ magnet (e.g., $500 \mathrm{MHz}$ for ${ }^{1} \mathrm{H}$ ). Samples were locked to the deuterated solvent and all chemical shifts reported in ppm referenced to tetramethylsilane. Mass spectra were recorded on a Waters Xevo G2-XS instrument. Solutions with concentrations of 0.001 molar were prepared in methanol and injected for analysis at a rate of $5 \mu \mathrm{L} / \mathrm{min}$ using a syringe pump.

\section{Synthesis of 4}

DMF $(250 \mathrm{~mL})$ and $\mathrm{H}_{2} \mathrm{O}(100 \mathrm{~mL})$ were added to a round bottom Schlenk flask $(500 \mathrm{~mL})$ and degassed with $\mathrm{N}_{2}$ for $2 \mathrm{~h}$. To this solvent mixture, 3 (1.11 g, $0.00325 \mathrm{~mol})$, 4-pyridylboronic acid $(1.00 \mathrm{~g}, 0.00814 \mathrm{~mol})$ and $\mathrm{Na}_{2} \mathrm{CO}_{3}(2.07 \mathrm{~g}$, $0.195 \mathrm{~mol}$ ) were added and the solution degassed for an additional $1 \mathrm{~h}$. Catalyst $\left[\mathrm{Pd}\left(\mathrm{PPh}_{3}\right)_{4}\right](0.188 \mathrm{~g}, 16.3 \mathrm{mmol})$ was added and the solution degassed for an additional $30 \mathrm{~min}$. The reaction was then refluxed for 5 days and the progress of the reaction monitored using ${ }^{1} \mathrm{H}$ NMR spectroscopy. After the 5 days, the reaction was cooled to room temperature and the solvents removed by evaporation. The residue was dissolved in $\mathrm{CH}_{2} \mathrm{Cl}_{2}(100 \mathrm{~mL})$ and washed with $\mathrm{H}_{2} \mathrm{O}(3 \times 50 \mathrm{~mL})$. The $\mathrm{CH}_{2} \mathrm{Cl}_{2}$ layer was dried over anhydrous $\mathrm{MgSO}_{4}$, filtered and concentrated. Compound $\mathbf{4}$ precipitated as a pale yellow powder which was collected by vacuum filtration. The filtrate was then evaporated under vacuum and the residue subjected to column chromatography $\left(\mathrm{SiO}_{2}, 1 \% \mathrm{MeOH} / \mathrm{CHCl}_{3}, R_{\mathrm{f}}=0.13\right)$ to yield further product. The batches of product (from precipitate and filtrate) were combined and recrystallized from acetone. Yield, 0.800 g, 73\%; mp $186-188{ }^{\circ} \mathrm{C} ;{ }^{1} \mathrm{H}$ NMR (500 MHz, $\mathrm{CD}_{3} \mathrm{CN}$, $298 \mathrm{~K}) \delta 8.60\left(\mathrm{~d},{ }^{3} J=6.1 \mathrm{~Hz}, 2 \mathrm{H}\right), 8.48\left(\mathrm{~d},{ }^{3} J=6.1 \mathrm{~Hz}, 2 \mathrm{H}\right)$, $7.71\left(\mathrm{~d},{ }^{3} J=8.2 \mathrm{~Hz}, 2 \mathrm{H}\right), 7.59\left(\mathrm{~d},{ }^{3} J=6.2 \mathrm{~Hz}, 2 \mathrm{H}\right), 7.54(\mathrm{~d}$, $\left.{ }^{3} J=8.7 \mathrm{~Hz}, 2 \mathrm{H}\right), 7.51\left(\mathrm{~d},{ }^{3} J=8.2 \mathrm{~Hz}, 2 \mathrm{H}\right), 7.49\left(\mathrm{~d},{ }^{3} J=6.2 \mathrm{~Hz}\right.$, $2 \mathrm{H}), 6.73\left(\mathrm{~d},{ }^{3} J=8.7 \mathrm{~Hz}, 2 \mathrm{H}\right), 5.41($ br t, $1 \mathrm{H}), 4.46(\mathrm{~d}$, $\left.{ }^{3} J=6.2 \mathrm{~Hz}, 2 \mathrm{H}\right) ;{ }^{13} \mathrm{C} \mathrm{NMR}\left(125 \mathrm{MHz}, \mathrm{CD}_{3} \mathrm{CN}, 298 \mathrm{~K}\right)$ $\delta 151.1,150.3,149.8,147.6,146.8,140.5,140.2,129.9,128.4$, 127.9, 127.6, 120.8, 120.4, 113.1, 47.6; HRMS (ESI) $\mathrm{m} / \mathrm{z}$ : $[\mathrm{M}+\mathrm{H}]^{+}$calcd for $\left[\mathrm{C}_{23} \mathrm{H}_{20} \mathrm{~N}_{3}\right]^{+}, 338.1657$; found, 338.1650.

\section{Synthesis of [7][OTf $]_{4}$}

[5][OTf $]_{2}(0.400 \mathrm{~g}, 0.626 \mathrm{mmol})$ and $6(2.61 \mathrm{~g}, 6.26 \mathrm{mmol})$ were dissolved in $\mathrm{CH}_{3} \mathrm{CN}(75 \mathrm{~mL})$ and stirred at room temperature for 7 days. The resulting precipitate was filtered, collected and stirred in $\mathrm{CH}_{2} \mathrm{Cl}_{2}$ for $20 \mathrm{~min}$ and filtered to remove excess 6. The precipitate was then anion exchanged to the triflate salt in a two-layer $\mathrm{CH}_{3} \mathrm{NO}_{2} / \mathrm{NaOTf}(\mathrm{aq})$ solution. The layers were separated and the $\mathrm{CH}_{3} \mathrm{NO}_{2}$ layer washed with $\mathrm{H}_{2} \mathrm{O}(3 \times 5 \mathrm{~mL})$ and then dried over anhydrous $\mathrm{MgSO}_{4}$. The $\mathrm{CH}_{3} \mathrm{NO}_{2}$ was removed by rotary evaporation and [7][OTf $]_{4}$ isolated as a pale yellow solid. Yield $0.700 \mathrm{~g}, 69 \%$; $\mathrm{mp}>180{ }^{\circ} \mathrm{C}$ (dec.); ${ }^{1} \mathrm{H}$ NMR $\left(500 \mathrm{MHz}, \mathrm{CD}_{3} \mathrm{CN}, 298 \mathrm{~K}\right) \delta 9.05\left(\mathrm{~d},{ }^{3} J=6.9 \mathrm{~Hz}, 4 \mathrm{H}\right), 9.04(\mathrm{~d}$, $\left.{ }^{3} J=6.9 \mathrm{~Hz}, 4 \mathrm{H}\right), 8.50\left(\mathrm{~d},{ }^{3} J=6.1 \mathrm{~Hz}, 4 \mathrm{H}\right), 8.47\left(\mathrm{~d},{ }^{3} J=6.1 \mathrm{~Hz}\right.$, $4 \mathrm{H}), 7.91(\mathrm{~s}, 2 \mathrm{H}), 7.86\left(\mathrm{~d},{ }^{3} J=8.2 \mathrm{~Hz}, 4 \mathrm{H}\right), 7.71$ (d, 
$\left.{ }^{3} J=8.2 \mathrm{~Hz}, 4 \mathrm{H}\right), 7.68\left(\mathrm{~d},{ }^{3} J=7.9 \mathrm{~Hz}, 2 \mathrm{H}\right), 7.67\left(\mathrm{~d},{ }^{3} J=8.2 \mathrm{~Hz}\right.$, $4 \mathrm{H}), 7.62\left(\mathrm{~d},{ }^{3} J=8.0 \mathrm{~Hz}, 4 \mathrm{H}\right), 7.57\left(\mathrm{t},{ }^{3} J=7.9,{ }^{3} J=8.1 \mathrm{~Hz}\right.$, 2H), $7.54\left(\mathrm{~d},{ }^{3} J=8.2 \mathrm{~Hz}, 4 \mathrm{H}\right), 5.89$ (s, 4H), 5.30 (br s, 4H), 4.66 (s, 4H); HRMS (ESI) $m / z$ : [M - OTf] $]^{+}$calcd, 1457.1114; found, 1457.1144 .

\section{Synthesis of [8 $\subset$ DB24C8][OTf] 6}

[7][OTf] 4 (0.155 g, $0.0963 \mathrm{mmol})$ and DB24C8 (0.432 g, $0.963 \mathrm{mmol}$ ) were dissolved in a two phase $\mathrm{CH}_{3} \mathrm{NO}_{2} / \mathrm{H}_{2} \mathrm{O}$ mixture and stirred at room temperature for $30 \mathrm{~min}$ to allow [2]pseudorotaxane formation. Compound $4(0.0330 \mathrm{~g}$, $0.0963 \mathrm{mmol})$ was then added along with NaOTf $(0.0330 \mathrm{~g}$, $0.193 \mathrm{mmol}$ ) and the reaction stirred at room temperature for 21 days. The water layer was separated and the $\mathrm{CH}_{3} \mathrm{NO}_{2}$ evaporated. The resulting residue was washed with $\mathrm{CH}_{2} \mathrm{Cl}_{2}$ $(3 \times 10 \mathrm{~mL})$ to remove excess DB24C8 and subjected to column chromatography on silica gel (5:3:2 mixture of $\mathrm{CH}_{3} \mathrm{OH} /$ $\left.\mathrm{NH}_{4} \mathrm{Cl}(2 \mathrm{M}) / \mathrm{CH}_{3} \mathrm{NO}_{2}\right)$. Fractions containing the product $\left(R_{\mathrm{f}}=0.66\right)$ were combined and the solvents evaporated. The residue was dissolved in a two layer $\mathrm{CH}_{3} \mathrm{NO}_{2} / \mathrm{NaOTf}(\mathrm{aq})$ solution to anion exchange to the triflate salt. The $\mathrm{H}_{2} \mathrm{O}$ layer was removed and the $\mathrm{CH}_{3} \mathrm{NO}_{2}$ layer washed with $\mathrm{H}_{2} \mathrm{O}(3 \times 5 \mathrm{~mL})$ to extract any remaining salts. The $\mathrm{CH}_{3} \mathrm{NO}_{2}$ layer was dried with anhydrous $\mathrm{MgSO}_{4}$ and then evaporated to yield [8CDB24C8][OTf $]_{6}$ as a yellow-orange solid. Yield $0.030 \mathrm{~g}$, $12 \%$; $\mathrm{mp}>210{ }^{\circ} \mathrm{C}\left(\mathrm{dec}\right.$.); HRMS (ESI) $\mathrm{m} / \mathrm{z}$ : $[\mathrm{M}-2 \mathrm{OTf}]^{2+}$ calcd for $\left[\mathrm{C}_{113} \mathrm{H}_{103} \mathrm{~F}_{12} \mathrm{~N}_{7} \mathrm{O}_{20} \mathrm{~S}_{4}\right]^{2+}, 1116.7969$, found, 1116.7972; $[\mathrm{M}-3 \mathrm{OTf}]^{3+}$ calcd for $\left[\mathrm{C}_{112} \mathrm{H}_{103} \mathrm{~F}_{9} \mathrm{~N}_{7} \mathrm{O}_{17} \mathrm{~S}_{3}\right]^{3+}, 694.8804$, found, 694.8835; $[\mathrm{M}-4 \mathrm{OTf}]^{4+} \mathrm{calcd}$ for $\left[\mathrm{C}_{111} \mathrm{H}_{103} \mathrm{~F}_{6} \mathrm{~N}_{7} \mathrm{O}_{14} \mathrm{~S}_{2}\right]^{4+}, 483.9222$, found, 483.9246; $[\mathrm{M}-5 \mathrm{OTf}]^{5+}$ calcd for $\left[\mathrm{C}_{110} \mathrm{H}_{103} \mathrm{~F}_{3} \mathrm{~N}_{7} \mathrm{O}_{11} \mathrm{~S}\right]^{5+}, 357.3472$, found, 357.3465; ${ }^{1} \mathrm{H} \mathrm{NMR}\left(500 \mathrm{MHz}, \mathrm{CD}_{2} \mathrm{Cl}_{2}, 298 \mathrm{~K}\right) \delta 9.31$ $\left(\mathrm{d},{ }^{3} J_{r q}=6.7 \mathrm{~Hz}, 2 \mathrm{H}, r\right), 9.31\left(\mathrm{~d},{ }^{3} J_{u v}=6.7 \mathrm{~Hz}, 2 \mathrm{H}, u\right), 9.03(\mathrm{~d}$, $\left.{ }^{3} J_{o p}=6.8 \mathrm{~Hz}, 2 \mathrm{H}, o\right), 9.03\left(\mathrm{~d},{ }^{3} J_{x w}=6.8 \mathrm{~Hz}, 2 \mathrm{H}, x\right), 8.76(\mathrm{~d}$, $\left.{ }^{3} J_{I J}=6.8 \mathrm{~Hz}, 2 \mathrm{H}, I\right), 8.49\left(\mathrm{~d},{ }^{3} J_{d c}=6.9 \mathrm{~Hz}, 2 \mathrm{H}, d\right), 8.22(\mathrm{~d}$, $\left.{ }^{3} J_{q r}=6.7 \mathrm{~Hz}, 2 \mathrm{H}, q\right), 8.22\left(\mathrm{~d},{ }^{3} J_{v u}=6.7 \mathrm{~Hz}, 2 \mathrm{H}, v\right), 8.22(\mathrm{~d}$, $\left.{ }^{3} J_{J I}=6.8 \mathrm{~Hz}, 2 \mathrm{H}, J\right), 8.19\left(\mathrm{~d},{ }^{3} J_{p o}=6.8 \mathrm{~Hz}, 2 \mathrm{H}, p\right), 8.19(\mathrm{~d}$, $\left.{ }^{3} J_{w x}=6.8 \mathrm{~Hz}, 2 \mathrm{H}, w\right), 8.04\left(\mathrm{~d},{ }^{3} J_{c d}=6.9 \mathrm{~Hz}, 2 \mathrm{H}, c\right), 7.87(\mathrm{~d}$, $\left.{ }^{3} J_{l m}=8.2 \mathrm{~Hz}, 2 \mathrm{H}, l\right), 7.87\left(\mathrm{~d},{ }^{3} J_{A z}=8.2 \mathrm{~Hz}, 2 \mathrm{H}, A\right), 7.87(\mathrm{~d}$, $\left.{ }^{3} J_{K L}=8.2 \mathrm{~Hz}, 2 \mathrm{H}, K\right), 7.83(\mathrm{~s}, 1 \mathrm{H}, k), 7.83(\mathrm{~s}, 1 \mathrm{H}, E), 7.80(\mathrm{~d}$, $\left.{ }^{3} J_{g f}=8.4 \mathrm{~Hz}, 2 \mathrm{H}, g\right), 7.78\left(\mathrm{~d},{ }^{3} J_{b a}=8.7 \mathrm{~Hz}, 2 \mathrm{H}, b\right), 7.77(\mathrm{~d}$, $\left.{ }^{3} J_{F G}=8.6 \mathrm{~Hz}, 2 \mathrm{H}, F\right), 7.74-7.70(\mathrm{~d}, 1 \mathrm{H}, h), 7.74-7.70(\mathrm{~d}, 1 \mathrm{H}$, j), 7.74-7.70 (d, $1 \mathrm{H}, B), 7.74-7.70(\mathrm{~d}, 1 \mathrm{H}, D), 7.64(\mathrm{~d}$, $\left.{ }^{3} J_{m l}=8.2 \mathrm{~Hz}, 2 \mathrm{H}, m\right), 7.64\left(\mathrm{~d},{ }^{3} J_{z A}=8.2 \mathrm{~Hz}, 2 \mathrm{H}, z\right), 7.62(\mathrm{dd}$, $1 \mathrm{H}, i), 97.62(\mathrm{dd}, 1 \mathrm{H}, C), 7.58\left(\mathrm{~d},{ }^{3} J_{L K}=8.2 \mathrm{~Hz}, 2 \mathrm{H}, L\right), 7.55$ $\left(\mathrm{d},{ }^{3} J_{G F}=8.6 \mathrm{~Hz}, 2 \mathrm{H}, G\right), 7.51\left(\mathrm{~d},{ }^{3} J_{f g}=8.4 \mathrm{~Hz}, 2 \mathrm{H}, f\right), 6.79(\mathrm{~d}$, $\left.{ }^{3} J_{a b}=8.7 \mathrm{~Hz}, 2 \mathrm{H}, a\right), 6.62\left(\mathrm{~m},{ }^{3} J_{\text {ortho }}=5.8,{ }^{3} J_{\text {meta }}=3.6 \mathrm{~Hz}\right.$, $4 \mathrm{H}, 1), 6.33\left(\mathrm{~m},{ }^{3} J_{\text {ortho }}=5.8,{ }^{3} J_{\text {meta }}=3.6 \mathrm{~Hz}, 4 \mathrm{H}, 2\right), 5.90(\mathrm{~s}$, $2 \mathrm{H}, n), 5.90(\mathrm{~s}, 2 \mathrm{H}, y), 5.87\left(\mathrm{t},{ }^{3} J_{N M}=5.6 \mathrm{~Hz}, 1 \mathrm{H}, N\right), 5.74(\mathrm{~d}$, $2 \mathrm{H}, H), 5.59(\mathrm{~s}, 2 \mathrm{H}, e), 5.56(\mathrm{~s}, 2 \mathrm{H}, s), 5.56(\mathrm{~s}, 2 \mathrm{H}, t), 4.48(\mathrm{~d}$, $\left.{ }^{3} J_{M N}=5.6 \mathrm{~Hz}, 2 \mathrm{H}, M\right), 4.04-3.99(\mathrm{~m}, 24 \mathrm{H}, 3-5)$.

\section{Acknowledgements}

The authors thank NSERC of Canada for funding; SJL for a Discovery grant and SJV for a post graduate scholarship. The authors acknowledge that the majority of this material was sourced from Vella, S. J. New Interlocked Molecular Machines. Ph.D. Thesis, University of Windsor, Windsor, ON, Canada, 2006.

\section{ORCID ${ }^{\circledR}$ iDs}

Stephen J. Loeb - https://orcid.org/0000-0002-8454-6443

\section{References}

1. Bruns, C. J.; Stoddart, J. F. The Nature of the Mechanical Bond; John Wiley \& Sons: Hoboken, New Jersey, 2017.

2. Stoddart, J. F. Angew. Chem., Int. Ed. 2017, 56, 11094-11125. doi:10.1002/anie.201703216

3. Anelli, P. L.; Spencer, N.; Stoddart, J. F. J. Am. Chem. Soc. 1991, 113, 5131-5133. doi:10.1021/ja00013a096

4. Zhu, K.; Vukotic, V. N.; Loeb, S. J. Angew. Chem., Int. Ed. 2012, 51, 2168-2172. doi:10.1002/anie.201108488

5. Vukotic, V. N.; Zhu, K.; Baggi, G.; Loeb, S. J. Angew. Chem., Int. Ed. 2017, 56, 6136-6141. doi:10.1002/anie.201612549

6. Bruns, C. J.; Stoddart, J. F. Acc. Chem. Res. 2014, 47, 2186-2199. doi:10.1021/ar500138u

7. Badjić, J. D.; Balzani, V.; Credi, A.; Silvi, S.; Stoddart, J. F. Science 2004, 303, 1845-1849. doi:10.1126/science.1094791

8. Thordarson, P.; Bijsterveld, E. J. A.; Rowan, A. E.; Nolte, R. J. M. Nature 2003, 424, 915-918. doi:10.1038/nature01925

9. Xue, M.; Yang, Y.; Chi, X.; Yan, X.; Huang, F. Chem. Rev. 2015, 115, 7398-7501. doi:10.1021/cr5005869

10. Ragazzon, G.; Baroncini, M.; Silvi, S.; Venturi, M.; Credi, A. Nat. Nanotechnol. 2015, 10, 70-75. doi:10.1038/nnano.2014.260

11. Berná, J.; Leigh, D. A.; Lubomska, M.; Mendoza, S. M.; Pérez, E. M.; Rudolf, P.; Teobaldi, G.; Zerbetto, F. Nat. Mater. 2005, 4, 704-710. doi:10.1038/nmat1455

12. Collier, C. P.; Mattersteig, G.; Wong, E. W.; Luo, Y.; Beverly, K.; Sampaio, J.; Raymo, F. M.; Stoddart, J. F.; Heath, J. R. Science 2000, 289, 1172-1175. doi:10.1126/science.289.5482.1172

13. Fahrenbach, A. C.; Warren, S. C.; Incorvati, J. T.; Avestro, A.-J.; Barnes, J. C.; Stoddart, J. F.; Grzybowski, B. A. Adv. Mater. 2013, 25 , 331-348. doi:10.1002/adma.201201912

14. Feringa, B. L. Angew. Chem., Int. Ed. 2017, 56, 11060-11078. doi:10.1002/anie.201702979

15. Cheng, C.; McGonigal, P. R.; Schneebeli, S. T.; Li, H.; Vermeulen, N. A.; Ke, C.; Stoddart, J. F. Nat. Nanotechnol. 2015, 10 , 547-553. doi:10.1038/nnano.2015.96

16. Vella, S. J.; Tiburcio, J.; Loeb, S. J. Chem. Commun. 2007, 4752-4754. doi:10.1039/b710708k

17. Hubbard, A. L.; Davidson, G. J. E.; Patel, R. H.; Wisner, J. A.; Loeb, S. J. Chem. Commun. 2004, 138-139. doi:10.1039/B312449E 18. Hart, H.; Rajakumar, P. Tetrahedron 1995, 51, 1313-1336. doi:10.1016/0040-4020(94)01016-S

19. Loeb, S. J.; Tiburcio, J.; Vella, S. J.; Wisner, J. A. Org. Biomol. Chem. 2006, 4, 667-680. doi:10.1039/b514528g

20. Attalla, M. I.; McAlpine, N. S.; Summers, L. A. Z. Naturforsch. 1984, 39b, 74-78. doi:10.1515/znb-1984-0113

21. Pan, J.; Han, X.; Sun, N.; Wu, H.; Lin, D.; Tien, P.; Zhou, H.-B.; Wu, S. RSC Adv. 2015, 5, 55100-55108. doi:10.1039/C5RA07286G 


\section{License and Terms}

This is an Open Access article under the terms of the Creative Commons Attribution License

(http://creativecommons.org/licenses/by/4.0). Please note that the reuse, redistribution and reproduction in particular requires that the authors and source are credited.

The license is subject to the Beilstein Journal of Organic Chemistry terms and conditions:

(https://www.beilstein-journals.org/bjoc)

The definitive version of this article is the electronic one which can be found at:

doi:10.3762/bjoc. 14.165 